\title{
Características químicas bromatológicas de plantas remanescentes a cultura do mini milho
}

\section{Bromatological chemical characteristics of the culture of the remaining plants babycorn}

\author{
ARCANJO JUNIOR, Hélio Gomes ${ }^{1}$; NASCIMENTO, Willian Gonçalves do ${ }^{2 *}$; MACEDO, \\ Italvan Milfont ${ }^{3}$; RODRIGUES, Carlos Ribeiro ${ }^{4}$; SOARES, Géssica Solanna Calado ${ }^{3 * *}$; \\ PEREIRA, Rodrigo Gomes ${ }^{1}$; SANTOS, Leones Costa dos ${ }^{1 *}$; SANTANA, Angélica Valsoní \\ da Silva ${ }^{3 * * *}$
}

\footnotetext{
${ }^{1}$ Universidade Federal Rural de Pernambuco, Programa de Pós-Graduação em Ciência Animal e Pastagens, Garanhuns, Pernambuco, Brasil.

${ }^{2}$ Universidade Federal do Paraná, Palotina, Paraná, Brasil / Universidade Federal Rural de Pernambuco, Programa de Pós-Graduação em Ciência Animal e Pastagens, Garanhuns, Pernambuco, Brasil

${ }^{3}$ Universidade Federal Rural de Pernambuco, Garanhuns, Pernambuco, Brasil. Bolsistas FACEPE, **PIBIC CNPq/UFRPE e ***PIC UFRPE.

${ }^{4}$ Instituto Federal Goiano, Rio Verde, Goiás, Brasil. Programa de Pós-Graduação em Ciência Animal e Pastagens, Garanhuns, Pernambuco, Brasil.

*Endereço para correspondência: williangoncalves@ufpr.br
}

\section{RESUMO}

Objetivou-se com este trabalho avaliar as características nutricionais, os cortes histológicos e a digestibilidade in vitro de plantas de milho colhidas no estágio de 90 dias após o plantio. Os tratamentos compreenderam cinco tipos de milho: um híbrido AG1051 e quatro cultivares de polinização aberta, e duas estratégias de colheita: milho planta inteira e plantas de milho sem espigas. As variedades de milho utilizadas foram: Alagoano, Branquinha, São Luiz e Viçosence. Os tratamentos foram ajustados em um delineamento em blocos ao acaso com três repetições em um esquema de parcelas subdivididas, com as variedades como parcelas principais e as estratégias de colheita como subparcelas. Dentre as variedades selecionadas, as que obtiveram os maiores valores para a PB no milho sem espiga foram as cultivares Alagoano e Viçosence. Para o NDT no milho sem espiga, as variedades que obtiveram os melhores valores $(\mathrm{P}<0,05)$ foram $\mathrm{o}$ AG1051, a Branquinha e o Viçosence, obtendo estas o maior potencial forrageiro diante as outras cultivares. Para o FDN e DIVFDN no milho sem espiga, a variedade que obteve os maiores valores $(\mathrm{P}<0,05)$ foi a Alagoano. Pode-se concluir que, sob o ponto de vista nutricional e estágio de colheita, todas variedades estudadas no experimento podem ser usadas na alimentação de ruminantes, com ou sem espigas.

Palavras chave: digestibilidade, forragem, qualidade

\section{SUMMARY}

The objective of this study was evaluate the nutritional value, histological sections and in vitro digestibility of maize plants harvested at the stage 90 days after planting. The treatments comprised five maize plant types: a hybrid AG1051 and four open-pollinated cultivars, and two harvest approaches: whole maize plants and maize plants without cobs. The maize varieties used were: Alagoano, Branquinha, St. Louis and Viçosence. The treatments were fitted into a randomized block design with three replicates in a split plot scheme, with maize varieties as main plots and harvest approaches as subplots. Among the varieties selected, those that had higher values for CP in maize plants without cobs were the Alagoano and Viçosence cultivars. For NDT in maize plants without cobs the varieties that had best results $(\mathrm{P}<0.05)$ were the AG1051, Branquinha and Viçosence. These varieties presented the greatest potential for forage production. For NDF and IVNDFD in maize plants without cobs the variety that had higher values $(\mathrm{P}<0.05)$ was the Alagoano. It can be concluded that, under the nutritional value and harvest stage, all the varieties studied in the trial can be used for ruminant feeding, with or without cobs.

Keywords: digestibility, forage, quality 


\section{INTRODUÇÃOO}

$\mathrm{O}$ milho em função do seu potencial produtivo e valor nutritivo é um dos mais importantes cereais cultivados e consumidos no mundo, devido à sua multiplicidade de aplicações, tanto na alimentação humana quanto na animal, e assume relevantes papéis socioeconômicos, além de ser indispensável matéria-prima para os diversificados complexos agroindustriais (LANA et al., 2012).

O milho possui fundamental papel entre as plantas forrageiras, pois apresenta alto rendimento de massa verde por hectare e alta qualidade nutricional podendo ser utilizado para a alimentação de ruminantes.

Embora a cultura do milho seja conhecida devido à produção de grãos secos e de forragem, a produção de milhos especiais (mini milho e milho verde) garante renda extra ao produtor, promovendo a abertura de um novo nicho de mercado, onde o mini milho por assumir grande versatilidade na alimentação humana, pode representar a pequenos produtores um retorno rápido e maior renda que a produção do milho grão.

A utilização das plantas remanescentes à colheita do mini milho para alimentação de animais ruminantes no período seco, na forma verde ou como silagem, pode ser uma alternativa de melhorar a rentabilidade do negócio.

Desta forma, além de estudar o potencial de novas variedades para a produção do mini milho, aliado à qualidade do resíduo forrageiro, é de suma importância para se obter materiais mais promissores.

Portanto, objetivou-se neste trabalho avaliar as características de composição química e a digestibilidade in vitro de cinco cultivares de plantas íntegras de milho (planta mais a espiga) e plantas remanescentes à colheita do mini milho (planta sem a espiga).

\section{MATERIAL E MÉTODOS}

$\mathrm{O}$ experimento foi realizado a campo no período de 03 de junho a 02 de setembro de 2011 na área experimental da Unidade Acadêmica de Garanhuns da Universidade Federal Rural de Pernambuco (UAG/UFRPE). O clima predominante da região de Garanhuns/PE é o Mesotérmico Tropical de Altitude (Cs'a), de acordo com a classificação climática de Köppen. Na Figura 1 são apresentados os dados de precipitação e temperatura média durante o período de realização do experimento (INMET, 2014).

O solo da área experimental é o Argissolo Amarelo (EMBRAPA, 2013). Para a caracterização da área experimental foi realizada amostragem e análise química do solo conforme EMBRAPA (2011). Os atributos químicos do solo na profundidade de 0 $-20 \mathrm{~cm}$ foram: $\mathrm{pH}$ em água: 4,82; MO: $35 \mathrm{~g} \mathrm{dm}^{-3} ; \mathrm{P}$ (Mehlich I): $35 \mathrm{gdm}^{-3}$; $\mathrm{H}+\mathrm{Al}, \mathrm{K}^{+}, \mathrm{Ca}^{2+} \mathrm{Mg}^{2+}$ e $\mathrm{T}$ apresentaram, respectivamente, 5,$1 ; 0,082 ; 2,5$ e $7,71 \mathrm{cmolc} \mathrm{dm}^{-3}$ e V de $34 \%$. Com base nos resultados da análise química do solo foi realizada a correção e adubação conforme recomendação para a cultura do milho para o estado de Pernambuco (IPA, 2008).

$\mathrm{O}$ delineamento experimental foi em blocos casualizados, em esquema fatorial $5 \times 2$ com parcela subdividida, sendo na parcela cinco cultivares de milho (AG1051, Alagoano, Branquinha, São Luiz e Viçosense) e nas subparcelas com e sem a colheita do mini milho, com três blocos. A parcela experimental foi constituída por seis linhas, espaçadas 
0,6m entre cada, por cinco metros de comprimento. A subparcela foi constituída de três linhas, espaçada $0,6 \mathrm{~m}$ entre cada por cinco metros de comprimento. Para a avaliação do experimento foi colhida a linha central de cada subparcela eliminando $0,5 \mathrm{~m}$ de cada extremidade. A área total para o experimento foi de $30 \times 40 \mathrm{~m}$. O estande de plantas final foi mantido em 62.500 plantas $\mathrm{ha}^{-1}$. Durante a condução do experimento foi realizado o controle de plantas daninhas com a aplicação em pré-emergência do herbicida Boxer ${ }^{\circledR}$ (alachlor $300 \mathrm{~g} \mathrm{~L}^{-1}+$ atrazine $180 \mathrm{~g} \mathrm{~L}^{-1}$ ) na dose de $8,0 \mathrm{~L} \mathrm{ha}^{-1}$.

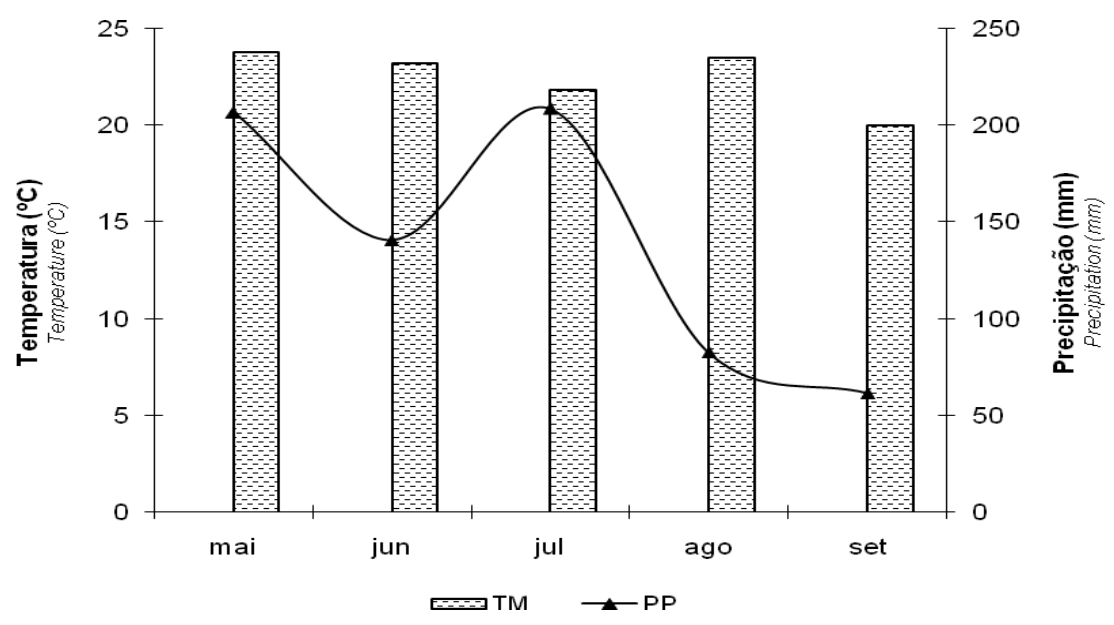

Figura 1. Dados de temperatura média e índices pluviométricos médios da época experimental

As colheitas do mini milho foram realizadas dois dias após a emissão dos estilos e dos estigmas, ou seja, 70 dias após a semeadura. As coletas das espiguetas foram realizadas a cada dois dias. A colheita das plantas dos diferentes tratamentos para as análises da composição química, digestibilidade in vitro e produção (matéria natural e matéria seca) ocorreram no estádio de grãos farináceos, ou seja, 90 dias após a semeadura.

Para a análise de produção, as plantas coletadas foram pesadas para a determinação da produção de matéria natural (PROD MN). Em seguida, o material foi picado em pedaços de $2,0 \mathrm{~cm}$ em forrageira convencional e seco em estufa com circulação forçada de ar a $65^{\circ} \mathrm{C}$ por 72 horas e pesadas para a determinação da produção da matéria seca (PROD MS). A seguir, as amostras foram moídas em moinho tipo faca (1,0mm de crivo) e acondicionadas em vasilhames plásticos previamente identificados e vedados. Esse material foi encaminhado ao Laboratório de Nutrição Animal (LANA/UAG) para as análises de composição química e de digestibilidade in vitro da fibra em Detergente Neutro (FDN).

A realização das análises de matéria seca (MS), matéria mineral (MM), proteína bruta $(\mathrm{PB})$ e extrato etéreo (EE) seguiram-se as metodologias da AOAC (1993). Para as análises de proteína insolúvel em detergente neutro (PIDN), proteína insolúvel em detergente ácido (PIDA), hemicelulose (HEM), celulose (CEL), lignina (LIG) foram adotadas as metodologias descritas por Silva \& Queiroz (2002). 
Rev. Bras. Saúde Prod. Anim., Salvador, v.17, n.3, p.344-354 jul./set., $2016 \quad$ http://www.rbspa.ufba.br

As análises de fibra em detergente neutro (FDN) e fibra em detergente ácido (FDA) foram realizadas de acordo com Van Soest (1991). Para a determinação do poder tampão (PT) foi utilizada a metodologia descrita por Palyne \& Mcdonald (1966). E para a estimativa dos nutrientes digestíveis totais (NDT), carboidratos totais (CT), carboidratos não fibrosos (CNF), frações A e B1, fração B e fração $C$ dos carboidratos foram utilizadas as equações descritas no NRC (2001).

A digestibilidade in vitro da FDN (DIVFDN) foi obtida segundo a metodologia descrita por Tilley \& Terry (1963), seguindo as modificações descritas por Holden (1999), com o uso do rúmen artificial desenvolvido pela TECNAL $^{\circledR}$. Para o ensaio da digestibilidade in vitro foi utilizado líquido ruminal de um bovino consumindo volumoso de pastagem de capim Tifton e capim elefante triturado e concentrado de farelo de milho. O programa estatístico utilizado foi o SAS versão 9.1, utilizando-se o teste de comparação de médias Scott-Knott a $\mathrm{P}<0,05$.

\section{RESULTADOS E DISCUSSÃO}

Os resultados obtidos para a produção de matéria natural (PROD MN) e produção de matéria seca (PROD MS) comparando as médias gerais das subparcelas, os maiores valores $(\mathrm{P}<0,05)$ foram obtidos pelas cultivares com a espiga e os menores valores obtidos nas subparcelas sem a espiga, em função da retirada das espiguetas do mini milho (Tabela 1).

Tabela 1. Produção de matéria natural (PROD MN) e produção de matéria seca (PROD MS) em $\mathrm{kg} / \mathrm{ha}$ de cinco cultivares de milho

\begin{tabular}{lcccc}
\hline Variáveis & \multicolumn{2}{c}{ PROD MN } & \multicolumn{2}{c}{ PROD MS } \\
\hline \multirow{2}{*}{ Cultivar } & \multicolumn{2}{c}{ Espiga } & Com & Sem \\
\cline { 2 - 5 } & Com & Sem & $13307,10^{\mathrm{A}}$ & $10670,93^{\mathrm{A}}$ \\
\hline AG1051 & $62499,75^{\mathrm{A}}$ & $43055,38^{\mathrm{B}}$ & $11685,76^{\mathrm{C}}$ & $8505,96^{\mathrm{B}}$ \\
Alagoano & $57221,99^{\mathrm{B}}$ & $36388,74^{\mathrm{B}}$ & $12388,13^{\mathrm{B}}$ & $10876,90^{\mathrm{A}}$ \\
Branquinha & $61110,86^{\mathrm{A}}$ & $53333,12^{\mathrm{A}}$ & $12517,66^{\mathrm{B}}$ & $9626,10^{\mathrm{A}}$ \\
São Luiz & $56110,88^{\mathrm{B}}$ & $43610,93^{\mathrm{B}}$ & $10842,83^{\mathrm{C}}$ & $8679,93^{\mathrm{B}}$ \\
Viçosence & $51230,90^{\mathrm{C}}$ & $45277,59^{\mathrm{B}}$ & $12148,30^{\mathrm{a}}$ & $9671,96^{\mathrm{b}}$ \\
\hline Média & $57634,70^{\mathrm{a}}$ & $44333,15^{\mathrm{b}}$ & \multicolumn{3}{c}{15,22} \\
\hline CV (\%) & \multicolumn{3}{c}{20,36} \\
\hline
\end{tabular}

Médias seguidas de diferentes letras maiúscula na coluna e minúsculas na linha diferem os tratamentos entre si pelo teste de $\operatorname{Scott} \operatorname{Knott}(\mathrm{P}<0,05)$.

A PROD MN na subparcela com a espiga, as variedades que obtiveram os maiores valores foram o AG1051 e a Branquinha. Na subparcela sem a espiga a variedade Branquinha obteve os maiores valores. Para a variável de PROD MS a cultivar AG1051 na subparcela com a espiga obteve o maior valor $(\mathrm{P}<0,05)$, no entanto dentre a subparcela sem espiga as cultivares que obtiveram os maiores valores $(\mathrm{P}<0,05)$ foram a AG1051, Branquinha e a São Luiz.

De acordo com Cruz \& Pereira Filho (2009) os híbridos são comumente mais precoces e mais produtivos que as 
cultivares de polinização aberta, entretanto neste ensaio a cultivar Branquinha que é de polinização aberta apresentou um rendimento de PROD MN semelhante ao hibrido testado.

Lucas et al. (2009) avaliaram o híbrido AG1051 para a produção e a qualidade do milho para silagem, e obtiveram valores em torno de 47,05 $\mathrm{t} \mathrm{ha}^{-1} \mathrm{de}$ PROD MN e 14,76 $\mathrm{t} \mathrm{ha}^{-1}$ de PROD MS, abaixo dos obtidos por este trabalho em relação à PROD MN. Possivelmente isto ocorreu pela maior idade ao corte das plantas avaliadas pelos autores acima citados, em torno de 120 dias e, portanto, maior perda de umidade das plantas. Os valores obtidos por estes autores são próximos aos obtidos neste trabalho para os resultados de PROD MS.

Analisando a variável da MS (Tabela 2) dentre os tratamentos analisados na subparcela com a espiga as cultivares que obtiveram as maiores médias foram o AG1051, Branquinha e São Luiz. No entanto para a subparcela sem espiga, as cultivares que obtiveram os maiores valores foram a AG1051, Branquinha e Viçosense. Comparando nas subparcelas as com ou sem espigas, o maior teor de MS na subparcela sem espigas, está relacionado a retirada das espiguetas do mini milho, o que segundo Fancelli \& Dourado Neto (2004), exige maior translocação de água e nutrientes da planta, para a formação de novas espiguetas e dos grãos. Portanto, a colheita das espiguetas do mini milho influenciaram no acréscimo de MS para a subparcela sem espiga.

Na Tabela 2 para a variável de $\mathrm{MM}$ as médias gerais das plantas sem espiga obtiveram os maiores valores $(\mathrm{P}<0,05)$ em comparação aos com a espiga, dentre as cultivares colhidas com espiga a Alagoano foi a que obteve o maior valor $46,63 \mathrm{~g} / \mathrm{kg}$ da $\mathrm{MS}$ de $\mathrm{MM}$
$(\mathrm{P}<0,05)$, e a cultivar AG1051 o que obteve o menor valor $(\mathrm{P}<0,05)$ para as cultivares sem espiga.

Os resultados obtidos neste trabalho, são próximos aos obtidos por Lucas et al. (2009) avaliando o híbrido AG1051com idade ao corte para silagem, obtendo valores em torno de $43,37 \mathrm{~g} / \mathrm{kg}$ da $\mathrm{MS}$ de MM próximo ao valor de 43,63g/kg obtido pelo AG1051 com espiga.

No entanto, Pereira (2011) avaliando plantas remanescentes a colheita do mini milho da cultivar AG1051 obteve valores superiores $(71,33 \mathrm{~g} / \mathrm{kg}$ da MS de MM) aos deste trabalho para a subparcela sem espiga (Tabela 2), possivelmente esta diferença está relacionada aos diferentes solos de cultivo.

Para a variável PB (Tabela 2) foram obtidos valores superiores $(\mathrm{P}<0,05)$ nas plantas com a espiga, sendo este resultado esperado, pois de acordo com Fancelli \& Dourado Neto (2004) os maiores teores de proteína bruta estão na espiga, quando comparado à planta (caules e folhas). Dentre as cultivares com espiga as variedades AG1051, Alagoano e Viçosense obtiveram os maiores valores, e dentre as cultivares sem espiga os maiores valores $(\mathrm{P}<0,05)$ foram para as cultivares Alagoano $\mathrm{e}$ Viçosense.

De acordo com Van Soest (1994), os requerimentos mínimos de $\mathrm{PB}$ para os microrganismos presentes no ruminante estão entre 6 e $8 \%$ de $\mathrm{PB}$, portanto as plantas remanescentes a cultura do mini milho podem ser fornecidas aos ruminantes. No entanto, sendo necessária uma suplementação proteica, uma vez que as plantas remanescentes a cultura do mini milho atingem o nível mínimo de PB requerido pelos microrganismos presentes no rúmen. 
Tabela 2. Composição químico-bromatológica e digestibilidade in vitro de plantas de milho, e das plantas remanescentes a colheita do mini milho

\begin{tabular}{|c|c|c|c|c|c|c|c|c|c|c|}
\hline \multirow{3}{*}{ Cultivar } & \multicolumn{2}{|c|}{$\mathrm{MS} \mathrm{g} / \mathrm{kg}$ de $\mathrm{MN}$} & \multicolumn{2}{|c|}{$\mathrm{MM} \mathrm{g} / \mathrm{kg}$ de $\mathrm{MS}$} & \multicolumn{2}{|c|}{$\mathrm{PB} \mathrm{g} / \mathrm{kg}$ de MS } & \multicolumn{2}{|c|}{ FDN g/kg de MS } & \multicolumn{2}{|c|}{ PIDN g/kg de MS } \\
\hline & \multicolumn{2}{|c|}{ Espiga } & \multicolumn{2}{|c|}{ Espiga } & \multicolumn{2}{|c|}{ Espiga } & \multicolumn{2}{|c|}{ Espiga } & \multicolumn{2}{|c|}{ Espiga } \\
\hline & Com & Sem & Com & Sem & Com & Sem & Com & Sem & Com & Sem \\
\hline AG1051 & $211,42^{\mathrm{aA}}$ & $218,37^{\mathrm{aA}}$ & $43,63^{\mathrm{aB}}$ & $40,55^{\mathrm{aB}}$ & $77,80^{\mathrm{aA}}$ & $64,03^{\mathrm{bB}}$ & $605,53^{\mathrm{bB}}$ & $632,43^{\mathrm{aB}}$ & $59,23^{\mathrm{a}}$ & $42,12^{\mathrm{bB}}$ \\
\hline Alagoano & $176,42^{\mathrm{bC}}$ & $204,75^{\mathrm{aB}}$ & $46,63^{\mathrm{aA}}$ & $47,58^{\mathrm{aA}}$ & $73,43^{\mathrm{aA}}$ & $69,82^{\mathrm{aA}}$ & $634,65^{\mathrm{bA}}$ & $683,60^{\mathrm{aA}}$ & $57,37^{\mathrm{a}}$ & $41,27^{\mathrm{bB}}$ \\
\hline Branquinha & $209,10^{\mathrm{aA}}$ & $215,37^{\mathrm{aA}}$ & $39,67^{\mathrm{bB}}$ & $43,70^{\mathrm{aA}}$ & $65,88^{\mathrm{aB}}$ & $62,92^{\mathrm{aB}}$ & $632,15^{\mathrm{aA}}$ & $589,82^{\text {bC }}$ & $54,42^{\mathrm{a}}$ & $46,05^{\mathrm{bA}}$ \\
\hline São Luiz & $192,17^{\mathrm{aA}}$ & $196,13^{\mathrm{aB}}$ & $42,30^{\mathrm{aB}}$ & $44,97^{\mathrm{aA}}$ & $70,85^{\mathrm{aB}}$ & $64,21^{\mathrm{bB}}$ & $629,43^{\mathrm{aA}}$ & $642,20^{\mathrm{aB}}$ & $53,62^{\mathrm{a}}$ & $47,85^{\mathrm{bA}}$ \\
\hline Viçosence & $195,28^{\mathrm{bB}}$ & $213,35^{\mathrm{aA}}$ & $42,43^{\mathrm{aB}}$ & $45,32^{\mathrm{aA}}$ & $75,23^{\mathrm{aA}}$ & $69,43^{\mathrm{bA}}$ & $616,73^{\mathrm{aB}}$ & $619,48^{\mathrm{aB}}$ & $56,50^{\mathrm{a}}$ & $45,65^{\mathrm{bA}}$ \\
\hline \multirow[t]{2}{*}{ Média } & $196,88^{\mathrm{b}}$ & $209,59^{\mathrm{a}}$ & $42,93^{\mathrm{b}}$ & $44,42^{\mathrm{a}}$ & $72,64^{\mathrm{a}}$ & $66,08^{\mathrm{b}}$ & $623,70^{\mathrm{a}}$ & $633,51^{\mathrm{a}}$ & $56,23^{\mathrm{a}}$ & $44,59^{\mathrm{b}}$ \\
\hline & \multicolumn{2}{|c|}{$\mathrm{CV}(\%)=6,55$} & \multicolumn{2}{|c|}{$\mathrm{CV}(\%)=6,26$} & \multicolumn{2}{|c|}{$\mathrm{CV}(\%)=6,82$} & \multicolumn{2}{|c|}{$\mathrm{CV}(\%)=3,04$} & \multicolumn{2}{|c|}{$\mathrm{CV}(\%)=8,34$} \\
\hline \multirow{3}{*}{ Cultivar } & \multicolumn{2}{|c|}{ FDA g/kg de MS } & \multicolumn{2}{|c|}{ PIDA g/kg de MS } & \multicolumn{2}{|c|}{ HEM g/kg de MS } & \multicolumn{2}{|c|}{ CEL g/kg de MS } & \multicolumn{2}{|c|}{ LIG g/kg de MS } \\
\hline & \multicolumn{2}{|c|}{ Espiga } & \multicolumn{2}{|c|}{ Espiga } & \multicolumn{2}{|c|}{ Espiga } & \multicolumn{2}{|c|}{ Espiga } & \multicolumn{2}{|c|}{ Espiga } \\
\hline & Com & Sem & Com & Sem & Com & Sem & Com & Sem & Com & Sem \\
\hline AG1051 & $366,93^{\mathrm{bB}}$ & $400,52^{\mathrm{a}}$ & $30,90^{\mathrm{aC}}$ & $20,55^{\mathrm{bC}}$ & $268,62^{\mathrm{aA}}$ & $231,92^{\mathrm{bB}}$ & $306,47^{\mathrm{bB}}$ & $367,37^{\mathrm{aB}}$ & $30,47^{\mathrm{aB}}$ & $33,15^{\mathrm{aB}}$ \\
\hline Alagoano & $383,13^{\mathrm{bA}}$ & $422,25^{\mathrm{a}}$ & $27,52^{\mathrm{aD}}$ & $25,62^{\mathrm{aB}}$ & $251,48^{\mathrm{aB}}$ & $261,32^{\text {aA }}$ & $354,43^{\mathrm{bA}}$ & $389,17^{\mathrm{aA}}$ & $28,72^{\mathrm{bB}}$ & $33,12^{\mathrm{aB}}$ \\
\hline Branquinha & $366,54^{\mathrm{bA}}$ & $415,75^{\mathrm{a}}$ & $47,37^{\mathrm{aA}}$ & $26,45^{\mathrm{bA}}$ & $265,63^{\mathrm{aA}}$ & $174,07^{\mathrm{bC}}$ & $333,73^{\mathrm{bA}}$ & $382,87^{\mathrm{aA}}$ & $32,82^{\mathrm{aA}}$ & $32,92^{\mathrm{aB}}$ \\
\hline São Luiz & $388,95^{\mathrm{aA}}$ & $408,55^{\mathrm{a}}$ & $37,97^{\mathrm{aB}}$ & $24,03^{\mathrm{bB}}$ & $240,52^{\mathrm{aB}}$ & $233,67^{\mathrm{aB}}$ & $359,45^{\mathrm{aA}}$ & $371,03^{\mathrm{aA}}$ & $29,50^{\mathrm{bB}}$ & $37,50^{\mathrm{aA}}$ \\
\hline Viçosence & $381,08^{\mathrm{aA}}$ & $396,28^{\mathrm{a}}$ & $30,90^{\mathrm{aC}}$ & $27,83^{\mathrm{bA}}$ & $235,63^{\mathrm{aB}}$ & $223,20^{\mathrm{aB}}$ & $344,83^{\mathrm{aA}}$ & $361,80^{\mathrm{aB}}$ & $36,25^{\mathrm{aA}}$ & $34,47^{\mathrm{aB}}$ \\
\hline \multirow[t]{2}{*}{ Média } & $371,33^{\mathrm{b}}$ & $408,67^{\mathrm{a}}$ & $34,93^{\mathrm{a}}$ & $24,90^{\mathrm{b}}$ & $252,38^{\mathrm{a}}$ & $224,83^{b}$ & $339,78^{b}$ & $374,45^{\mathrm{a}}$ & $31,55^{b}$ & $34,23^{\mathrm{a}}$ \\
\hline & $\mathrm{CV}$ & 4,52 & $\mathrm{CV}$ & 5,42 & $\mathrm{CV}$ & $=7,19$ & $\mathrm{CV}($ & $=5,09$ & $\mathrm{CV}(\%$ & 9,11 \\
\hline & DIVFDI & de MS & PT eq. m & $\mathrm{HCl} / 100 \mathrm{~g}$ & CT g/ & le MS & $\mathrm{CNF} g$ & de MS & NDT g/l & de MS \\
\hline Cultivar & & & & & & & & & & \\
\hline & Com & Sem & Com & Sem & Com & Sem & Com & Sem & Com & Sem \\
\hline AG1051 & $202,25^{\mathrm{a}}$ & $213,77^{\mathrm{aC}}$ & $22,87^{\mathrm{bC}}$ & $26,12^{\mathrm{a}}$ & $857,80^{\mathrm{bB}}$ & $878,63^{\mathrm{a}}$ & $260,80^{\mathrm{a}}$ & $252,30^{\mathrm{aB}}$ & $626,28 a^{A}$ & $620,13^{\mathrm{aA}}$ \\
\hline Alagoano & $220,70^{\mathrm{b}}$ & $269,38^{\mathrm{aA}}$ & $33,33^{\mathrm{aA}}$ & $28,85^{\mathrm{b}}$ & $867,87^{\mathrm{aA}}$ & $873,70^{\mathrm{a}}$ & $241,72^{\mathrm{a}}$ & $196,22^{\mathrm{bC}}$ & $622,87^{\mathrm{aA}}$ & $600,50^{\mathrm{bB}}$ \\
\hline Branquinha & $213,15^{\mathrm{a}}$ & $231,60^{\mathrm{aC}}$ & $25,87^{\mathrm{aC}}$ & $26,93^{\mathrm{a}}$ & $876,07^{\mathrm{aA}}$ & $879,33^{\mathrm{a}}$ & $251,87^{\mathrm{b}}$ & $296,32^{\mathrm{aA}}$ & $608,48^{\mathrm{bB}}$ & $625,97^{\mathrm{aA}}$ \\
\hline São Luiz & $215,83^{b}$ & $247,50^{\mathrm{aB}}$ & $24,93^{\mathrm{bC}}$ & $28,48^{\mathrm{a}}$ & $868,43^{\mathrm{aA}}$ & $875,32^{\mathrm{a}}$ & $246,67^{\mathrm{a}}$ & $239,93^{\mathrm{aB}}$ & $615,67^{\mathrm{aB}}$ & $605,08^{\mathrm{aB}}$ \\
\hline Viçosence & $208,52^{\mathrm{a}}$ & $221,63^{\mathrm{aC}}$ & $28,20^{\mathrm{aB}}$ & $28,40^{\mathrm{a}}$ & $876,07^{\mathrm{bB}}$ & $871,92^{\mathrm{a}}$ & $254,60^{\mathrm{a}}$ & $259,12^{\mathrm{aB}}$ & $614,80^{\mathrm{aB}}$ & $613,43^{\mathrm{aA}}$ \\
\hline Média & $212,09^{b}$ & $236,78^{a}$ & 27,04 & 27,76 & $866,63^{b}$ & $875,78^{\mathrm{a}}$ & $251,13^{\mathrm{a}}$ & $248,78^{\mathrm{b}}$ & 617,73 & 613,02 \\
\hline & $\mathrm{CV}($ & 7,33 & $\mathrm{CV}$ & 8,31 & $\mathrm{CV}$ & $=0,78$ & $\mathrm{CV}($ & 8,54 & $\mathrm{CV}(\%$ & 1,56 \\
\hline
\end{tabular}

Médias seguidas de diferentes letras minúsculas na linha e maiúscula na coluna diferem estatisticamente pelo teste de Scott Knott (P<0,05). Matéria seca (MS), matéria mineral (MM), proteína bruta (PB), fibra em detergente neutro (FDN), proteína insolúvel em detergente neutro (PIDN), fibra em detergente ácido (FDA), proteína insolúvel em detergente ácido (PIDA), hemicelulose (HEM), celulose (CEL), lignina (LIG), digestibilidade in vitro da fibra em detergente neutro (DIVFDN), poder tampão (PT), carboidratos totais $(\mathrm{CT})$, carboidratos não fibrosos $(\mathrm{CNF})$, nutrientes digestíveis totais (NDT). 
Para os valores da FDN comparando as médias gerais das cultivares com e sem a espiga não obtiveram diferença significativa $(\mathrm{P}>0,05)$. Dentre as cultivares com a espiga o híbrido AG1051 e a cultivar Viçosense obtiveram os menores valores $(\mathrm{P}<0,05)$. Dentre os tratamentos sem a espiga foi observado que a cultivar Alagoano obteve o maior valor $(\mathrm{P}<0,05)$.

Para os resultados da PIDN (Tabela2) avaliando as cultivares com e sem espiga foram encontrados os maiores valores $(\mathrm{P}<0,05)$ para a média geral das cultivares com espiga. Dentre as cultivares com espiga não foi observada diferença significativa $(\mathrm{P}>0,05)$, para as cultivares sem espiga os maiores valores foram obtidos pelas cultivares Branquinha, São Luiz e Viçosense.

Em relação aos valores de FDA (Tabela 2) comparando as médias gerais das cultivares com e sem a espiga, as cultivares sem a espiga obtiveram os maiores valores $(\mathrm{P}<0,05)$. Nas cultivares com espiga o híbrido AG1051 obteve o menor valor. Para a subparcelas em a espiga não houve diferença significativa $(\mathrm{P}>0,05)$ dentre os tratamentos.

De acordo com dados de Pereira (2011) a FDA indica a quantidade de fibra que é pouco digestível, sendo um indicador do valor energético da forragem e da silagem de milho. Quanto menor o seu valor, maior o valor energético do alimento, portanto a cultivar AG1051 com a espiga obteve os melhores resultados diante das outras parcelas.

$\mathrm{Na}$ análise da variável da PIDA comparando as subparcelas com e sem a espiga as cultivares com a espiga obtiveram os maiores valores $(\mathrm{P}<0,05)$. Entre as cultivares com a espiga o que obteve o maior valor $(\mathrm{P}<0,05)$ foi a cultivar Branquinha, e nas subparcelas sem a espiga o híbrido AG1051 obteve o menor valor (Tabela2).
A PIDA contém a proteína associada à lignina, taninos e compostos de Maillard, altamente resistentes à degradação microbiana e enzimática, sendo considerada inaproveitável, tanto no rúmen como no intestino (Sniffen et al., 1992).

Nas avaliações da variável HEM para as subparcelas as cultivares com a espiga obtiveram os maiores valores $(\mathrm{P}<0,05)$. Entre os tratamentos com a espiga os que obtiveram os maiores valores $(\mathrm{P}<0,05)$ foram o híbrido AG1051 e a cultivar Branquinha, dentre as cultivares sem a espiga a que obteve o maior valor $(\mathrm{P}<0,05)$ foi a cultivar Alagoano (Tabela 2).

Para os dados publicados no CQBAL em 2012, os autores avaliaram o híbrido AG1051 com a espiga, obtendo valores em torno de $259,00 \mathrm{~g} / \mathrm{kg}$ de $\mathrm{MS}$ de HEM próximos aos obtidos neste trabalho na subparcela com a espiga.

Para as avaliações da celulose (CEL) na Tabela 2, comparando as subparcelas, a com a espiga obteve o menor valor $(\mathrm{P}<0,05)$. Na subparcela com a espiga a que obteve o menor valor $(\mathrm{P}<0,05)$ foi o híbrido AG1051, e para a subparcela sem a espiga o híbrido AG1051 e a cultivar Viçosense foram os que obtiveram os menores valores $(\mathrm{P}<0,05)$. Os dados publicados no CQBAL (2012) para a variedade AG1051 com a espiga obteve os valores abaixo dos obtidos neste trabalho, possivelmente pela maior idade ao corte das plantas.

$\mathrm{Na}$ Tabela 2 para a variável lignina (LIG) as subparcelas que obtiveram os maiores valores $(\mathrm{P}<0,05)$ foram as sem a espiga. Para o tratamento com a espiga as cultivares Branquinha $\mathrm{e}$ Viçosense obtiveram os maiores valores $(\mathrm{P}<0,05)$. Em meio as cultivares sem a espiga a que obteve o maior valor $(\mathrm{P}<0,05)$ foi a São Luiz. Para os valores de lignina publicados no CQBAL (2012) observou-se valores inferiores 
aos deste trabalho, em torno de $28,00 \mathrm{~g} /$ $\mathrm{kg}$ de MS para as plantas com espiga.

Na DIVFDN comparando os tratamentos com e sem a espiga as que obtiveram os maiores valores foram as cultivares sem a espiga $(\mathrm{P}<0,05)$. Entre as cultivares com a espiga não houve diferença estatística $(\mathrm{P}>0,05)$. Dentre os tratamentos sem a espiga a que obteve o maior valor $(\mathrm{P}<0,05)$ foi a cultivar Alagoano (Tabela2). Possivelmente a DIVFDN da cultivar Alagoano sem a espiga foi maior, porque está relacionado aos maiores valores obtidos por este no FDN.

Para a variável de Poder Tampão (PT) na Tabela 2, não houve valores significativos $(\mathrm{P}>0,05)$ entre os tratamentos com e sem a espiga, e nem entre as cultivares sem a espiga, mas a cultivar que obteve o maior valor $(\mathrm{P}<0,05)$ entre as cultivares com a espiga foi a cultivar Alagoano.

Utilizando-se os dados de poder tampão (PT) como parâmetro de boa fermentação para a silagem de milho de 15 a 25 eq. $\mathrm{mg}$ de $\mathrm{HCl} / 100 \mathrm{~g}$ MS de acordo com McDonald (1981), as cultivares AG1051 e São Luiz, ambas com a espiga, encontram-se dentro da faixa preconizada por este autor. Todavia, o PT da massa a ser ensilada pode ser alterado também pelo teor de umidade da forragem no momento da ensilagem, um manejo simples como a alocação das plantas para emurchecimento aumentam o seu poder tampão McDonald (1981).

Nas análises de carboidratos totais (CT) (Tabela2) as cultivares sem a espiga obtiveram os maiores valores $(\mathrm{P}<0,05)$, quando comparados aos com a espiga. Dentre as cultivares sem a espiga não houve diferença estatística $(\mathrm{P}>0,05)$. Para a subparcela com a espiga o híbrido AG1051 e a cultivar Viçosense foram as que obtiveram os menores valores $(\mathrm{P}<0,05)$.

Para os carboidratos não fibrosos $\mathrm{CNF}$ (Tabela2) na subparcela com a espiga não foi observado diferença estatística
$(\mathrm{P}>0,05)$. Dentre as cultivares sem a espiga a que obteve o maior valor foi a Branquinha $(\mathrm{P}<0,05)$.

Os valores obtidos pelas cultivares colhido com a espiga (Tabela 2) estão em torno de $251,13 \mathrm{~g} \mathrm{CNF} / \mathrm{kg}$ de MS, sendo estes superiores aos colhidos sem a espiga, possivelmente porque os $\mathrm{CNF}$ representam os compostos de açucares, glicose, frutose, ácidos orgânicos, sacarose, frutosanas e outros carboidratos de reserva, tais como amido em alta quantidade presentes nas espigas de milho.

Para os valores obtidos de NDT não houve diferença estatística $(\mathrm{P}>0,05)$ entre as subparcelas, no entanto, na subparcela com a espiga as cultivares que obtiveram os maiores valores $(\mathrm{P}<0,05)$ foram $\mathrm{o}$ AG1051 e Alagoano. Nos tratamentos sem a espiga os que obtiveram os menores valores $(\mathrm{P}<0,05)$ foram as cultivares Alagoano e São Luiz.

Os valores obtidos por Lucas et al. (2009) e Fancelli \& Dourado Neto (2004) utilizando o híbrido AG1051 para a confecção de silagem obtiveram valores superiores aos deste trabalho, em torno de 650,0 e $670 \mathrm{~g} / \mathrm{kg}$ de NDT da MS, respectivamente.

Para a fração A e B1 dos carboidratos em meio as subparcelas as que obtiveram os maiores valores $(\mathrm{P}<0,05)$ foram as com a espiga (Tabela 3 ).

Entre as cultivares com a espiga não houve diferença significativa dentre os tratamentos $\quad(\mathrm{P}>0,05)$. Para os tratamentos sem a espiga a que obteve $\mathrm{o}$ maior valor $(\mathrm{P}<0,05)$ foi a cultivar Branquinha, coincidentemente a maior $\mathrm{CNF}$, portanto a maior quantidade de frações rapidamente digestíveis, uma vez que de acordo com Rodrigues et al. (2011), a fração A e B1 dos carboidratos são frações rapidamente digestíveis e influenciam diretamente na digestibilidade. Dentro desse grupo, estão os carboidratos de baixo peso 
Rev. Bras. Saúde Prod. Anim., Salvador, v.17, n.3, p.344-354 jul./set., $2016 \quad$ http://www.rbspa.ufba.br ISSN 15199940

molecular, ou seja, glicose, dissacarídeos e ácidos orgânicos. Assim sendo, a maior porcentagem desta fração acarretará em maior qualidade nutricional do alimento.

Para a fração B2 dos carboidratos ou porção pouco ou parcialmente digestível, dentre as subparcelas as que obtiveram os maiores valores $(\mathrm{P}<0,05)$ foram as sem a espiga. Para as cultivares com a espiga não houve diferença estatística $(\mathrm{P}>0,05)$. Dentre os tratamentos sem a espiga a cultivar que obteve o maior valor foi a Alagoano podendo possivelmente explicar o porquê da alta DIVFDN desta cultivar, ou seja, maior proporção de fibra dessa variedade.

Tabela 3. Fracionamento dos carboidratos de plantas de milho e das plantas remanescentes a colheita do mini milho

\begin{tabular}{lcccccc}
\hline & \multicolumn{2}{c}{ Fração A e B1 g/kg de MS } & \multicolumn{2}{c}{ Fração B2 g/kg de MS } & \multicolumn{2}{c}{ Fração C g/kg de MS } \\
\hline \multirow{2}{*}{ Cultivar } & \multicolumn{2}{c}{ Espiga } & \multicolumn{2}{c}{ Espiga } & \multicolumn{2}{c}{ Espiga } \\
\cline { 2 - 6 } & Com & Sem & Com & Sem & Com & Sem \\
\hline AG1051 & $360,08^{\mathrm{a}}$ & $324,08^{\mathrm{bB}}$ & $636,82^{\mathrm{b}}$ & $671,78^{\mathrm{aB}}$ & 3,12 & 4,12 \\
Alagoano & $332,03^{\mathrm{a}}$ & $261,98^{\mathrm{bC}}$ & $665,13^{\mathrm{b}}$ & $735,58^{\mathrm{aA}}$ & 2,82 & 2,42 \\
Branquinha & $336,62^{\mathrm{b}}$ & $378,52^{\mathrm{aA}}$ & $659,45^{\mathrm{a}}$ & $618,33^{\mathrm{bC}}$ & 3,92 & 3,12 \\
São Luiz & $333,22^{\mathrm{a}}$ & $318,38^{\mathrm{aB}}$ & $663,18^{\mathrm{a}}$ & $679,10^{\mathrm{aB}}$ & 3,58 & 2,53 \\
Viçosense & $348,67^{\mathrm{a}}$ & $338,07^{\mathrm{aB}}$ & $649,03^{\mathrm{a}}$ & $658,10^{\mathrm{aB}}$ & 2,32 & 3,80 \\
\hline Média & $342,12^{\mathrm{a}}$ & $324,20^{\mathrm{b}}$ & $652,72^{\mathrm{b}}$ & $672,58^{\mathrm{a}}$ & 3,15 & 3,20 \\
\hline & \multicolumn{2}{c}{$\mathrm{CV}(\%)=7,47$} & \multicolumn{2}{c}{$\mathrm{CV}(\%)=3,66$} & $\mathrm{CV}(\%)=47,84$
\end{tabular}

Médias seguidas de diferentes letras minúsculas na linha e maiúscula na coluna diferem estatisticamente pelo teste de Scott-Knott $(\mathrm{P}<0,05)$.

A fração $\mathrm{C}$ não apresentou diferença estatística por ser uma planta muito jovem e possuir pouca lignina. De acordo com Nussio et al. (2011) o conteúdo de lignina das forragens é muito variável, ainda que se mantenham em quantidades proporcionais, onde à medida que avança a maturação fisiológica de uma planta aumenta o conteúdo de lignina.

Assim sendo, as cultivares estudadas neste experimento do ponto de vista nutricional podem ser utilizadas na alimentação de ruminantes, com ou sem as espigas. Entretanto, independente das cultivares, os materiais remanescentes da colheita do mini milho (sem espiga), devem ser testados em ensaios de desempenho animal e avaliação de custos. A fim de esclarecer melhor o uso ou não destes recursos adicionais que outrora são desprezados ou descartados no meio ambiente de qualquer forma.

\section{REFERÊNCIAS}

ASSOCIATION OF OFFICIAL ANALYTICAL CHEMISTS - AOAC. Official methods of analysis. 15. ed. Arlington: AOAC International, 1993.

\section{CQBAL, 3.0 Composição Química e} Bromatológica dos Alimentos. [2012]. Disponível em: $<$ http://cqbal.agropecuaria.ws/webcqbal /bin/relatorios/filtroAlimentos.php $>$. Acesso em 30 jun. 2013. 
Rev. Bras. Saúde Prod. Anim., Salvador, v.17, n.3, p.344-354 jul./set., 2016 http://www.rbspa.ufba.br ISSN 15199940

CRUZ, J.C.; PEREIRA FILHO, I.A. Cultivo de milho. [2009]. Disponível em:

$<$ http://www.cnpms.embrapa.br/publica coes/milho 5 ed/cultivares.htm>. Acessado em 20 set. 2013.

EMPRESA BRASILEIRA DE PESQUISA AGROPECUÁRIA EMBRAPA. Sistema brasileiro de classificação de solos. 3.ed. Brasília, 2013. 353p.

EMPRESA BRASILEIRA DE PESQUISA AGROPECUÁRIA EMBRAPA. Manual de métodos de análises de solos. 2. ed. Rio de Janeiro: Embrapa Solos, 2011. 230 p. (Documentos, 132).

FANCELLI, L.A.; DOURADO NETO, D. Produção de Milho. 2 ed. Guaíba: Agropecuária, 2004. 360p.

FERREIRA, G.D.G.; BARRIÈRE, Y.; EMILE, J.C.; JOBIM, C.C.; ALMEIDA, O. C. - Valor nutritivo da silagem de dez híbridos de milho. Acta Scientiarum. Animal Sciences, v.33, n.3, p.255-260, 2011.

HOLDEN, L.A. Comparison of methods of in vitro matter digestibility for ten feeds. Journal of Dairy Science, v.2, p.1791-1794, 1999.

INMET - INSTITUTO NACIONAL DE METEOROLOGIA. 2014.

Disponível em:

$<$ http://www.inmet.gov.br/portal/>. Acessado em 20 jan. 2014.

IPA. EMPRESA PERNAMBUCANA DE PESQUISA AGROPECUÁRIA.

Recomendações de Adubação para o Estado de Pernambuco. 2.ed. Recife, 2008. 198p.
LANA, L.O.; GUERRA, J.G.M.; ESPINDOLA, J.A.A.; ARAÚJO, E.S. Avaliação de genótipos de milho com dupla aptidão para produção de mini milho e biomassa para adubação verde. Seropédica, RJ: Embrapa Agrobiologia, 2012. 20p. (Boletim de pesquisa e desenvolvimento, 85 ).

LUCAS, F.T.; SEKITA, A.P.C.; SILVA, F.H.; FERNANDES, L.O. Produção e qualidade de híbridos de milho para silagem. FAZU em Revista, n.6, p.11-52, 2009.

McDONALD, P. The Biochemistry of Silage. Chichester: John Wiley, 1981. $128 \mathrm{p}$.

NATIONAL RESEARCH COUNCIL NRC. Nutrient requirements of dairy cattle. 7 ed. Washington, D.C.: National Academy of Science, 2001. p.381.

NUSSIO, L.G.; CAMPOS, F.P.; LIMA, M. L.M. Metabolismo de carboidratos estruturais In: BERCHIELLI, T. T.; PIRES, A. V.; OLIVEIRA, S. G. (Ed) Nutrição de Ruminantes. Jaboticabal: Funep, 2011. p.193-238.

PALYNE, M.J.; McDONALD, P. The buffering constituents of herbage and silage. Journal Science of Food and Agriculture, v.17. p.264-268, 1966.

PEREIRA, R.S. Desempenho agronômico e forrageiro de mini milho e milho verde em diferentes épocas de semeadura e idades de corte das plantas remanescentes. 2011. 129p. Dissertação (Mestrado) Universidade Estadual de Montes Claros. 
Rev. Bras. Saúde Prod. Anim., Salvador, v.17, n.3, p.344-354 jul./set., $2016 \quad \underline{\text { http://www.rbspa.ufba.br }}$

RODRIGUES, M.T.; VIEIRA, R.A.M.

Metodologias aplicadas ao

fracionamento de alimentos In:

BERCHIELLI, T.T.; PIRES, A.V.;

OLIVEIRA, S.G. (Ed). Nutrição de

Ruminantes. Jaboticabal: Funep, 2011. p.29-59.

SILVA, D.J.; QUEIROZ, A.C. Análises de alimentos: métodos químicos e biológicos. 3. ed. Viçosa, MG: Editora UFV, 2002. 235p.

SNIFFEN, C.J.; O’ CONNOR, J.D.; VAN SOEST, P.J.; RUSSELL, J.B. A net carbohydrate and protein system for evaluating cattle diets: II. Carbohydrate and protein availability. Journal

Animal Science, v.70, n.10, p.35623577, 1992.

TILLEY, J.M.; TERRY, R.A. A twostage technique for the in vitro digestion of forage crops. Journal of British

Grass land Society, v.18, p.104-111, 1963.

VANSOEST, P.J.; ROBERTSON, J.B.; LEWIS, B.A. Methods for dietary fiber, neutral detergent fiber, and non-starch polysaccharides in relation to animal nutrition. In: Symposium Carbohydrate Methodology, Metabolism, and Nutritional Implications in Dairy Cattle. Journal of Dairy Science, v.74, n.10, p.3583-3597, 1991.

VAN SOEST, P.J.; Nutritional ecology of the ruminant. 2. ed. Ithaca, New York: Cornell University, 1994. 476p.

Data de recebimento: 09/02/2015

Data de aprovação: 22/07/2016 